\title{
Compensação tamanho/densidade populacional de perfilhos em pastos de capim-marandu
}

\author{
André Fischer Sbrissia ${ }^{1^{*}}$, Sila Carneiro da Silva ${ }^{2}$ \\ 1 Programa de Pós-graduação em Agronomia - Escola Superior de Agricultura "Luiz de Queiroz" - Departamento de Zootecnia. Avenida Pádua \\ Dias, 11 - 13418-900, Caixa Postal 9, Piracicaba, SP, Brasil. \\ 2 Universidade de São Paulo - Escola Superior de Agricultura "Luiz de Queiroz" - Departamento de Zootecnia. Avenida Pádua Dias, 11 - CEP: \\ 13418-900, Caixa Postal 9, Piracicaba, SP, Brasil. Pesquisador do CNPq.
}

RESUMO - Este trabalho foi realizado para verificar a existência de relação entre tamanho e número de perfilhos em pastos de capim-marandu e testar se ajustes relacionados a variações em índice de área foliar (IAF), relação área foliar:volume por perfilho (R) e densidade aparente de perfilhos na equação de predição da resposta permitiriam explicar eventuais desvios da inclinação teórica predita. Foram avaliadas quatro condições da pastos $(10,20,30$ e $40 \mathrm{~cm}$ de altura), mantidas constantes por bovinos em regime de lotação contínua e taxa de lotação variável. O delineamento experimental foi o de blocos completos casualizados com quatro repetições. Avaliaram-se a densidade populacional de perfilhos, a massa por perfilho, a área foliar por perfilho, o índice de área foliar, a relação folha/colmo e a razão área foliar:volume do perfilho (R). Além disso, regressões lineares simples foram realizadas para a avaliação dos parâmetros da relação funcional entre densidade populacional e massa por perfilho. As medições foram realizadas de janeiro a dezembro de 2002. Pastos de capim-marandu possuem um mecanismo de compensação tamanho/densidade populacional de perfilhos pelo qual maiores densidades populacionais estão associadas a perfilhos pequenos e vice-versa. Os valores de $\mathrm{R}$ apresentaram variações sazonais, indicando que perfilhos desta espécie podem reduzir área foliar em relação ao seu volume como mecanismo de sobrevivência em condições de déficit hídrico. As análises de regressão revelaram coeficientes lineares menores que $-3 / 2$, de modo que os desvios desta expectativa foram explicados pelas variações registradas em IAF, R e na densidade aparente de perfilhos.

Palavras-chave: alturas de pastejo, auto-desbaste, Brachiaria brizantha, densidade populacional, lei do -3/2, perfilhamento

\section{Tiller size/density compensation in Marandu palisadegrass swards}

\begin{abstract}
The objectives of this study were to evaluate the existence of a relationship between tiller size and tiller number in grazed palisadegrass swards and to verify if adjustments related to changing in leaf area index (LAI), leaf area:tiller volume ratio $(\mathrm{R})$, and tiller bulk density in the prediction equation of the response would explain eventual slope deviation from the theoretical predict slope. Treatments corresponded to four sward "steady state" conditions (10, 20, 30, and 40 $\mathrm{cm}$ sward surface heights), maintained by cattle under continuous but variable stocking rate. The experimental design was a complete randomized block design with four replicates and the response-variables evaluated were tiller population density, mean tiller weight, and leaf area per tiller. Sward leaf area index (LAI), tiller leaf:stem ratio, and tiller leaf area:volume ratio $(\mathrm{R})$ were calculated and simple regression analyses between tiller population density and tiller weight in a logarithm scale were performed. Measurements were made from January to December 2002. Swards showed a tiller size/density compensation mechanism characterized by high tiller population densities associated with small tillers and vice-versa. Rvalues showed a seasonal pattern of variation, suggesting that tillers of this grass species would be able to reduce leaf area in relation to its volume as a response to water deficit conditions. Calculated regression coefficients were smaller than the theoretical expectation of $-3 / 2$ and such deviation was satisfactorily explained by the recorded variations in LAI, R and tiller bulk density.
\end{abstract}

Key Words: Brachiaria brizantha, -3/2 law, grazing heights, population density, self-thinning, tillering

Este artigo foi recebido em 26/6/2006 e aprovado em 13/7/2007.

Correspondências devem ser enviadas para sbrissia@cav.udesc.br

Endereço atual: Universidade do Estado de Santa Catarina - Centro Agroveterinário - Departamento de Zootecnia. Avenida Luiz de Camões, 2090 - CEP: $88520-000$, Lages, SC, Brasil. 


\section{Introdução}

A relação inversa entre densidade populacional e tamanho individual de perfilhos em comunidades de plantas forrageiras submetidas a desfolhação tem sido descrita para muitos pastos de gramíneas (Grant et al., 1983; Lambert et al., 1986; Davies, 1988). Em relvados que não sofreram desfolhação, a compensação tamanho/densidade foi observada segundo uma reta de inclinação -3/2 (detalhes sobre o conceito podem ser obtidos em Yoda et al., 1963; Westoby, 1984; Matthew et al., 1995; Sackville-Hamilton et al., 1995; Pretzch, 2002), exceto em condições de baixa luminosidade (Kays \& Harper, 1974; Lonsdale \& Watkinson, 1982). Apesar disso, em relvados sob desfolhação, alguns autores têm observado falta sistemática de ajuste à inclinação teórica de -3/2 (Matthew, 1992; Hernandez-Garay et al., 1999; Sbrissia et al., 2001, 2003). Segundo Matthew et al. (1995), em pastos sob desfolhação, um diagrama multifásico de compensação tamanho/densidade seria esperado, onde existiriam quatro fases, cada uma delas representando diferentes situações do estado do pasto, que explicariam as alterações nos padrões de variação e a interação número $\times$ peso de perfilhos individuais no pasto. Esse equilíbrio é tão dinâmico que as respostas compensatórias entre tamanho e densidade populacional de perfilhos em comunidades de plantas submetidas a desfolhação podem fazer com que variações grandes entre regimes de desfolhação, resultem em apenas pequenas diferenças na quantidade total de folhas produzidas por unidade de área ou índice de área foliar (IAF), como demonstrado em estudos com pastos sob lotação contínua mantidas em diferentes alturas de dossel(Grant et al., 1983; Bircham \& Hodgson, 1983). Além disso, SackvilleHamilton et al. (1995) demonstraram que uma reta de inclinação -3/2 seria uma expectativa teórica quando o IAF e a razão entre área foliar e o tamanho da planta $(\mathrm{R})$ permanecessem constantes. Considerando que a área foliar varia durante a rebrotação ou em resposta à intensidade de desfolhação (Bircham \& Hodgson, 1983; Matthew et al., 1995; Fagundes et al., 1999), é natural que a compensação tamanho/densidade populacional em pastos submetidos à desfolhação assuma inclinações diferentes de -3/2. Correções para essas variações em IAF e $\mathrm{R}$ foram propostas for Matthew et al. (1995) e denominadas $\mathrm{C}_{\mathrm{a}}$ e $\mathrm{C}_{\mathrm{r}-}$, respectivamente, que representam uma mudança vertical hipotética na reta $-3 / 2$ e explicam os desvios entre os valores de inclinação normalmente mensurados e o valor previsto de $-3 / 2$. Além disso, esses mesmos autores consideraram a possibilidade de que variações em massa por unidade de volume dos perfilhos (densidade aparente) também pudessem explicar os desvios da reta $-3 / 2$. Em razão das dificuldades na mensuração do volume de perfilhos individuais, variável necessária para o cálculo da densidade aparente, esta última hipótese não pôde ser confirmada pelos autores.

No ambiente tropical, são poucos os estudos envolvendo a compensação tamanho/densidade populacional de perfilhos. O conhecimento desse mecanismo pode ajudar a compreender os limites plásticos de comunidades de perfilhos em pastos e determinar alternativas de manejo do pastejo que não comprometam a persistência do pasto e favoreçam a otimização dos processos de produção e utilização da forragem produzida. Dessa forma, os objetivos neste trabalho foram avaliar a compensação tamanho/densidade populacional de perfilhos em pastos de capimmarandu e verificar se as inclinações obtidas para as curvas entre $\log$ da densidade populacional e $\log$ da massa de perfilhos individuais poderiam ser explicadas pelas variações no IAF, na razão área foliar:volume (R) e na densidade aparente dos perfilhos. Com base nestas respostas, procurou-se identificar estratégias de manejo que maximizem a produtividade e a persistência do capim-marandu.

\section{Material e Métodos}

O experimento foi conduzido na Unidade Experimental de Plantas Forrageiras (UEPF), em área do Departamento de Zootecnia da Escola Superior de Agricultura Luiz de Queiroz, da Universidade de São Paulo, em Piracicaba, SP (22 $42^{\prime}$ S, $47^{\circ} 37^{\prime} \mathrm{W}, 550 \mathrm{~m}$ altitude) em pastos de capim-marandu (Brachiaria brizantha Hochst. ex A. Rich cv. Marandu) estabelecidos em setembro de 2000. O solo da área é um Nitossolo Vermelho eutroférrico, com horizonte A moderado e textura variando de argilosa a muito argilosa (EMBRAPA, 1999) de alta fertilidade. A análise de solo realizada antes do período experimental revelou os seguintes valores: $\mathrm{P}=$ $67 \mathrm{mg} / \mathrm{dm}^{3}$ (resina trocadora de íons; Van Raij et al., 1986); $\mathrm{MO}=41 \mathrm{~g} / \mathrm{dm}^{3} ; \mathrm{pH}\left(\mathrm{CaCl}_{2}\right)=5,6 ; \mathrm{K}=6,5 \mathrm{mmol}_{\mathrm{c}} / \mathrm{dm}^{3} ; \mathrm{Ca}=$ $74 \mathrm{mmol}_{\mathrm{c}} / \mathrm{dm}^{3} ; \mathrm{Mg}=19 \mathrm{mmol} / \mathrm{dm}^{3} ; \mathrm{H}+\mathrm{Al}=36 \mathrm{mmol}_{\mathrm{c}} / \mathrm{dm}^{3}$; $\mathrm{CTC}=135,0 \mathrm{mmol}_{\mathrm{c}} / \mathrm{dm}^{3} ;$ saturação de bases $=74 \% . \mathrm{Em}$ virtude da elevada fertilidade, somente adubações nitrogenadas (e eventualmente potássicas) foram realizadas durante o período experimental (Tabela 1). Segundo o sistema Köppen, o clima da região de Piracicaba é classificado como Cwa, ou seja, mesotérmico úmido, subtropical de inverno seco (Figuras 1 e 2).

O experimento foi realizado em delineamento de blocos completos casualizados, com quatro repetições. Os tratamentos corresponderam a quatro alturas de dossel forrageiro $(10,20,30$ e $40 \mathrm{~cm})$, mantidas "constantes" por meio da 
Tabela 1 - Datas, doses e tipos de fertilizantes utilizados durante o período experimental

\begin{tabular}{lccc}
\hline Data & $\begin{array}{c}\text { Nitrogênio } \\
(\mathrm{kg} / \mathrm{ha})\end{array}$ & $\begin{array}{c}\text { Potássio } \\
\left(\mathrm{kg} / \mathrm{ha} \text { de } \mathrm{K}_{2} \mathrm{O}\right)\end{array}$ & Fertilizante \\
\hline $7 / 11 / 2001$ & 66 & & Nitrato de amônio \\
$1 / 12 / 2001$ & 30 & 20 & 30.00 .20 \\
$10 / 1 / 2002$ & 45 & 30 & 30.00 .20 \\
$7 / 3 / 2002$ & 115 & & Uréia \\
$30 / 10 / 2002$ & 46 & 50 & Uréia \\
Total & 302 & 50 & \\
\hline
\end{tabular}

adição e/ou retirada de animais das unidades experimentais. Portanto, durante todo o período de avaliação, adotou-se a técnica de lotação contínua com taxa de lotação variável. Para manutenção das condições experimentais, foram utilizados bovinos de corte das raças Nelore e Canchim obtidos do plantel do Departamento de Zootecnia da USP/ESALQ. Dessa forma, o experimento foi realizado com um total de 16 unidades experimentais ou parcelas $(4$ blocos $\times 4$ unidades

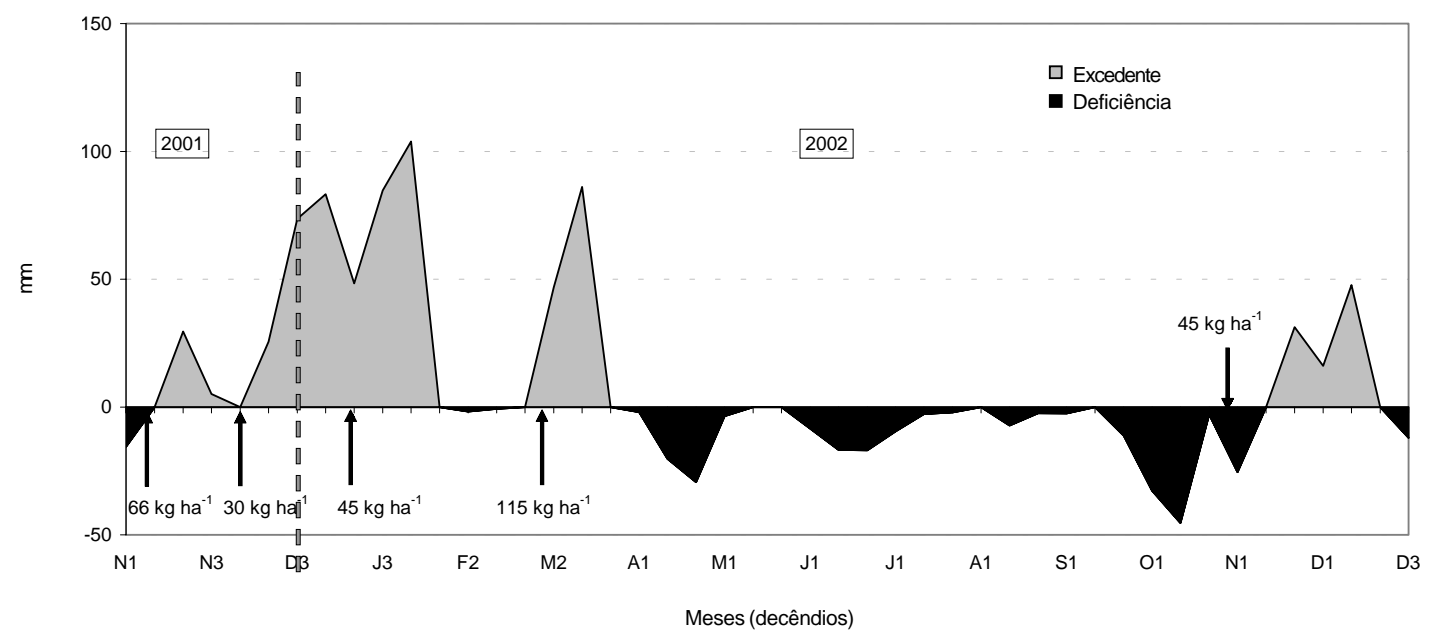

Figura 1 - Extrato do balanço hídrico dos decêndios mensais do período de novembro de 2001 a dezembro de 2002 e épocas de adubação nitrogenada * Os símbolos no eixo $\mathrm{X}$ indicam as iniciais dos meses de cada ano. Dessa forma, N1 corresponde ao primeiro decêndio do mês de novembro e assim sucessivamente.

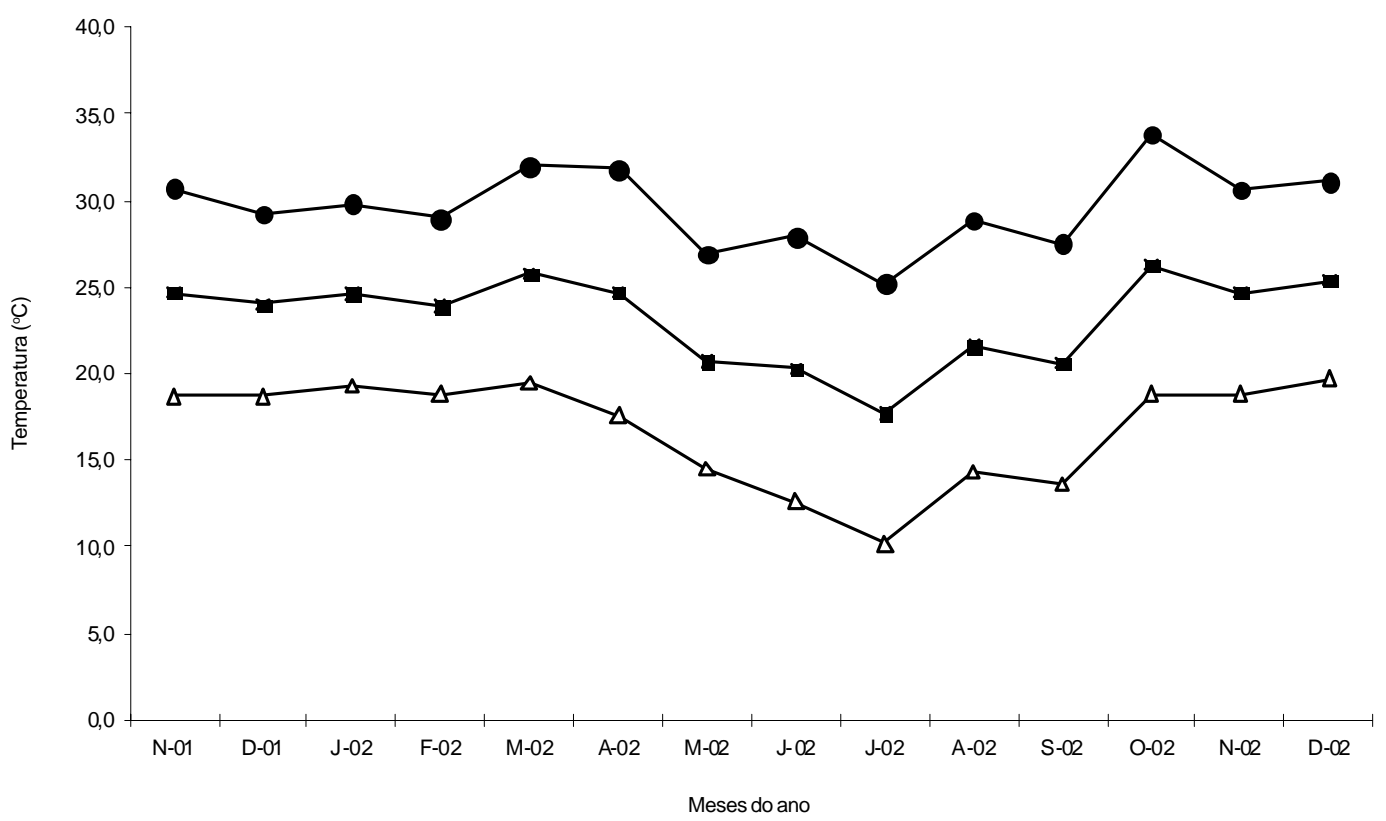

Figura 2 - Temperaturas médias $(\boldsymbol{\square})$, médias mínimas $(\Delta)$ e médias máximas $(\bullet)$ durante o período experimental. 
experimentais por bloco), com área média de $1.200 \mathrm{~m}^{2}$ cada, totalizando aproximadamente 2 ha. O período experimental teve início em 8 de janeiro e término em 17 de dezembro de 2002, totalizando 343 dias.

Antes do período de avaliação, a área foi submetida a um corte de uniformização realizado por meio de roçadeira na altura de $8 \mathrm{~cm}$ do solo durante os dias 28 e 29 de agosto de 2001. Em seguida, iniciou-se o monitoramento da altura do dossel e os animais foram adicionados às parcelas à medida que estas se tornaram próximas às metas de altura dos tratamentos.O monitoramento da altura foi realizado a intervalos de 3 e 4 dias (duas vezes por semana), em 20 pontos por unidade experimental, com ouso de transparência e régua (Fagundes et al., 1999; Pedreira, 2002). Estabeleceu-se uma amplitude de variação de $10 \%$ para os valores de altura média dos tratamentos e, conforme o limite superior ou o inferior foram ultrapassados, os animais foram adicionados ou removidos das parcelas, respectivamente. Ao final do mês de outubro de 2001, todas as parcelas já se encontravam sob pastejo, o que assegurou um período de aproximadamente 60 dias de equilíbrio entre o estabelecimento das condições de pasto planejadas e o início das avaliações (Figura 3).

Para as avaliações mensais das características individuais dos perfilhos, 60 perfilhos foram coletados em cada unidade experimental. Todos os perfilhos colhidos foram acondicionados em sacos plásticos, rapidamente levados à câmara fria para resfriamento $\left(4^{\circ} \mathrm{C}\right)$ e minimização dos efeitos de respiração e transpiração das plantas e, posteriormente, foram processados.

Inicialmente, os 60 perfilhos colhidos foram pesados em balança digital, de modo que os valores obtidos, divididos pelos mesmos 60 perfilhos, resultaram na massa de matéria fresca média por perfilho. Após a pesagem, os perfilhos tiveram seus volumes medidos em equipamento construído especificamente para essa finalidade (Sbrissia et al., 2004). Posteriormente, foram separados de cada perfilho as lâminas foliares verdes e o material morto e senescente e o colmo (colmo + bainha das folhas). A área foliar das lâminas verdes foi medida em aparelho integrador de área foliar, marca LI-COR, modelo LI-3100. Cada componente foi acondicionado em pequenos sacos de papel e levado para estufa de ventilação forçada a $65^{\circ} \mathrm{C}$ por 48 horas. Após secagem, os sacos foram pesados em balança digital. A área foliar específica $\left(\mathrm{cm}^{2} / \mathrm{g}\right)$ foi obtida a partir do quociente entre a área foliar e a massa de MS de folhas por perfilho.

A relação folha:colmo (FC) foi obtida a partir do quociente entre a massa de MS de lâminas foliares e a massa de MS de colmos. Durante o verão e o outono, o material morto não foi separado dos demais componentes, pois, durante esse período do ano, fazia parte do componente colmo. A razão área foliar:volume por perfilho (R), proposta por Sackville-Hamilton et al. (1995), foi calculada utilizando-se a expressão:

$$
R=\frac{A_{f}^{3 / 2}}{V}
$$

em que: $\mathrm{R}$ = razão área foliar:volume por perfilho; $\mathrm{A}_{\mathrm{f}}=$ área foliar média por perfilho $\left(\mathrm{m}^{2}\right)$; e $\mathrm{V}=$ volume médio por perfilho $\left(\mathrm{m}^{3}\right)$.

Os cálculos foram realizados de duas formas. Na primeira, assumiu-se uma densidade aparente dos perfilhos constante de $950 \mathrm{~kg} / \mathrm{m}^{3}$ (Sbrissia et al., 2001,2003) e, a partir

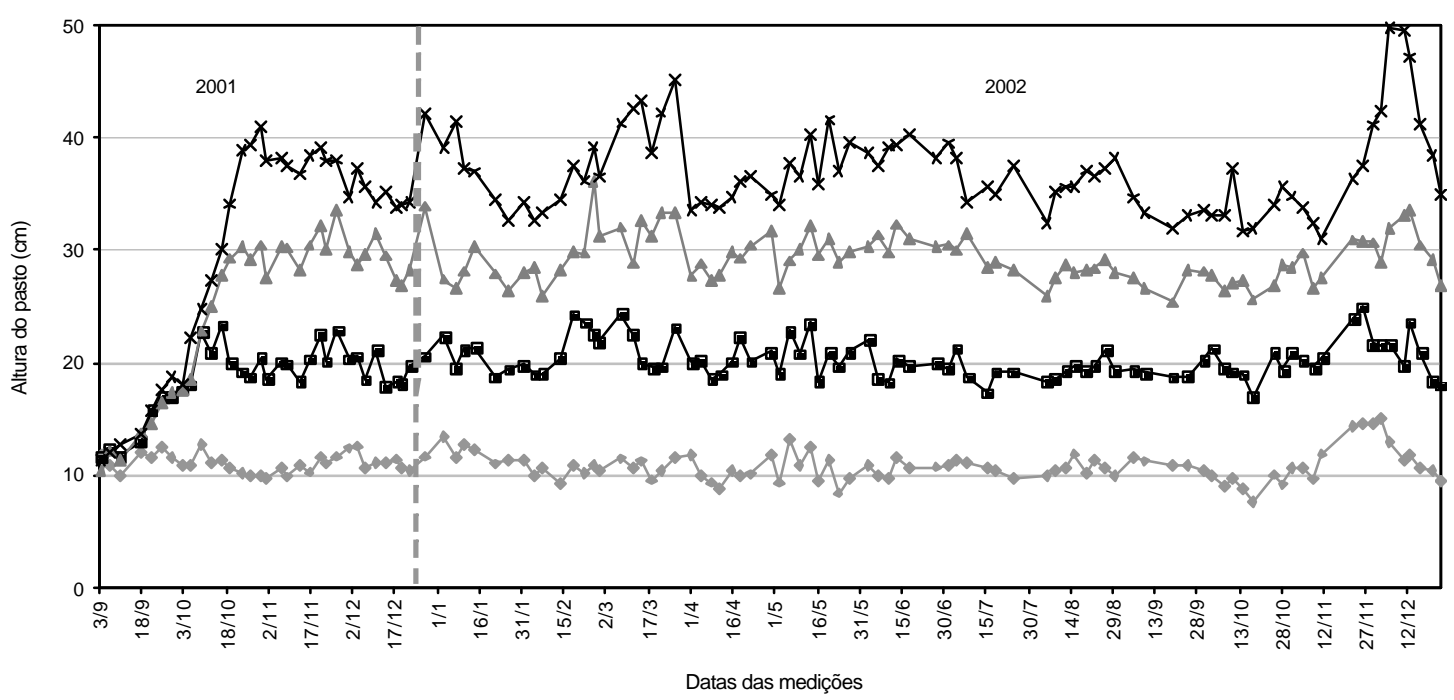

Figura 3 - Valores médios das alturas dos pastos ao longo do período experimental. 
desse valor e da massa de matéria verde por perfilho, foram gerados os valores de volume utilizados no cálculo da variável R. Alternativamente, os valores de R foram calculados utilizando-se os valores de volume medidos de forma direta (Sbrissia et al., 2004) utilizando-se aparelho específico. Como as medições de volume apresentaram valores consistentes apenas a partir de julho, esta última forma de cálculo só foi possível para as avaliações realizadas de julho a dezembro de 2002.

As estimativas de densidade populacional de perfilhos foram obtidas com o uso de armações metálicas de $0,25 \mathrm{~m}^{2}$ $(100 \times 25 \mathrm{~cm})$. Foram utilizados três retângulos por unidade experimental, alocados em pontos representativos da condição dos pastos (altura média) no momento da amostragem. As avaliações foram realizadas mensalmente e todos os perfilhos vivos no interior da armação metálica foram contados. Optou-se pelo uso de uma medida retangular visando englobar, dentro do possível, a grande heterogeneidade verificada em pastos de capim-marandu.

Os dados de densidade populacional, massa de MS por perfilho e índice de área foliar foram inicialmente calculados com base nos meses do ano e plotados para visualização de possíveis padrões de variação ao longo do tempo. A análise gráfica dos dados permitiu a identificação de períodos em que o comportamento das variáveis estudadas foi homogêneo, razão pela qual se optou por agrupar os valores mensais da seguinte forma: verão: janeiro, fevereiro e março; outono: abril, maio e junho; inverno: julho e agosto; início de primavera: setembro e outubro; final de primavera: novembro e dezembro.

O agrupamento dos dados de dois em dois meses a partir de julho foi realizado com o objetivo de isolar os meses de setembro e outubro em um período único. Nesses dois meses, os pastos apresentaram padrões de resposta excepcionalmente diferentes dos demais, mas semelhantes entre si. Como houve mudança na metodologia de avaliação do volume dos perfilhos durante o experimento, os dados de volume, densidade aparente e razão área foliar:volume por perfilho foram analisados somente para os períodos de inverno e início e final de primavera. Os dados agrupados foram analisados utilizando-se o procedimento MIXED (modelos mistos) do pacote estatístico SAS ${ }^{\circledR}$ (Statistical Analysis System), versão 8.2 para Windows ${ }^{\circledR}$. Na escolha da matriz de variância e covariância, utilizou-se o Critério de Informação de Akaike (Wolfinger, 1993). Assim, foi possível detectar os efeitos das causas de variação principais (altura

Tabela 2 - Densidade populacional de perfilhos (perfilhos $/ \mathrm{m}^{2}$ ) em pastos de capim-marandu mantidos em quatro alturas de dossel forrageiro por meio de lotação contínua em diferentes épocas do ano

\begin{tabular}{|c|c|c|c|c|c|c|}
\hline \multirow[t]{2}{*}{ Época do ano } & \multicolumn{4}{|c|}{ Altura $(\mathrm{cm})$} & \multirow[t]{2}{*}{ Média } & \multirow[t]{2}{*}{ Erro-padrão da média } \\
\hline & 10 & 20 & 30 & 40 & & \\
\hline Verão & 1.301 & 1.178 & 1.059 & 914 & $1.113 \mathrm{~A}$ & 22 \\
\hline Outono & 1.081 & 1.009 & 969 & 746 & $951 \mathrm{~B}$ & 22 \\
\hline Inverno & 958 & 877 & 656 & 523 & $753 \mathrm{D}$ & 22 \\
\hline Início primavera & 949 & 831 & 665 & 486 & $732 \mathrm{D}$ & 22 \\
\hline Final primavera & 934 & 881 & 830 & 658 & $826 \mathrm{C}$ & 22 \\
\hline Erro-padrão da média & 18 & 18 & 18 & 18 & & \\
\hline
\end{tabular}

Médias seguidas da mesma letra minúscula na linha e maiúscula na coluna não diferem $(P>0,10)$ pelo teste $t$.

Tabela 3 - Massa de MS média por perfilho $(\mathrm{mg})$ em pastos de capim-marandu mantidos em quatro alturas de dossel forrageiro por meio de lotação contínua em diferentes épocas do ano

\begin{tabular}{|c|c|c|c|c|c|c|}
\hline \multirow[t]{2}{*}{ Época do ano } & \multicolumn{4}{|c|}{ Altura (cm) } & \multirow[t]{2}{*}{ Média } & \multirow[t]{2}{*}{ Erro-padrão da média } \\
\hline & 10 & 20 & 30 & 40 & & \\
\hline Verão & $308,1 \mathrm{dC}$ & $644,2 \mathrm{cBC}$ & $826,3 b D$ & $1.262,5 \mathrm{aB}$ & $760,3 \mathrm{C}$ & 20,19 \\
\hline Outono & $329,2 \mathrm{dC}$ & $585,6 \mathrm{cC}$ & $979,2 \mathrm{bC}$ & $1.104,9 \mathrm{aC}$ & $749,7 \mathrm{C}$ & 21,77 \\
\hline Inverno & $385,2 \mathrm{dBC}$ & $718,8 \mathrm{cB}$ & $1.181,5 \mathrm{bB}$ & $1.347,6 \mathrm{aB}$ & $908,3 \mathrm{~B}$ & 34,99 \\
\hline Início primavera & $513,5 \mathrm{dA}$ & $919,7 \mathrm{cA}$ & $1.333,0 \mathrm{bA}$ & $1.588,6 \mathrm{aA}$ & $1.088,7 \mathrm{~A}$ & 39,77 \\
\hline Final primavera & $468,9 \mathrm{dAB}$ & $647,2 \mathrm{cBC}$ & $1.053,7 \mathrm{bC}$ & $1.220,3 \mathrm{aBC}$ & $847,5 \mathrm{~B}$ & 34,21 \\
\hline Erro-padrão da média & 22,78 & 22,78 & 22,78 & 22,78 & & \\
\hline
\end{tabular}

Médias seguidas de mesma letra minúscula na linha e maiúscula na coluna não diferem $(P>0,10)$ pelo teste $t$.

Erro-padrão da média da interação: verão $=40,38$, outono $=43,54$, inverno $=69,98$, início da primavera $=79,54$ e final da primavera $=68,42$ 
e época do ano) e a interação entre essas causas. Os efeitos de altura do dossel e época do ano e de suas interações foram considerados fixos e o efeito de blocos foi considerado aleatório (Littel et al., 2000). As médias entre tratamentos foram estimadas utilizando-se o LSMEANS, e a comparação entre elas foi realizada por meio da probabilidade da diferença (PDIFF) utilizando-se o teste t de Student a $10 \%$ de significância.

No caso das regressões lineares usadas nos cálculos dos parâmetros (Sackville-Hamilton et al., 1995) da compensação tamanho/densidade populacional de perfilhos, utilizou-se o programa PAST $^{\circledR}$, que calcula os coeficientes angulares das regressões pelo método do "eixo maior reduzido" (do inglês, Reduced Major Axis, ou RMA), que é particularmente preferido nesse caso (Sackville-Hamilton et al., 1995), no qual ocorre erro amostral nos dois eixos (LaBarbera, 1989).

\section{Resultados e Discussão}

Como o objetivo foi manter os pastos em diferentes alturas (variável controle), não foi realizada análise de variância nem testadas possíveis interações altura $\times$ época. Os pastos tiveram pequenas variações nas alturas pretendidas ao longo do ano (Figura 3). Apesar disso, ao longo de praticamente todo o ano, as diferenças entre as alturas foi suficiente para que estruturas contrastantes de pasto fossem criadas e permitissem a comparação entre elas. Além disso, a coleta de todos os dados apresentados neste trabalho foi realizada em locais em que o pasto se encontrava com a altura pretendida. Os valores de densidade populacional de perfilhos (DDP; Tabela 2) corroboram vários resultados disponíveis na literatura, que indicam decréscimo na população de perfilhos à medida que os pastos são mantidos mais altas (Parsons et al., 1983a; Bircham \& Hodgson, 1983; Matthew et al., 1995; Sbrissia et al., 2001, 2003). Essa competição entre perfilhos ocorre particularmente por luz (Lonsdale \& Watkinson, 1982; Sackville-Hamilton et al., 1995), ou seja, a baixa intensidade luminosa na base do relvadoé, reconhecidamente, um dos principais fatores que interferem na capacidade de perfilhamento de pastos mantidos mais altos.

Em trabalho conduzido na mesma área, de forma concomitante, Molan (2004) observou que a partir da altura de $20 \mathrm{~cm}$ pastos de capim-marandu já interceptavam mais que $95 \%$ da luz incidente. Desse modo, torna-se evidente que a competição já estava ocorrendo e, provavelmente, induzindo uma mortalidade de perfilhos dependente de luz. Peternelli (2003), trabalhando com a mesma planta forrageira, verificou valores ligeiramente superiores de
DPP em pastos submetidos a intensidades variáveis de pastejo rotacionado.

Os maiores valores de massa de MS dos perfilhos foram registrados em perfilhos provenientes de pastos mantidos mais altos (Tabela 3 ). Esse fato, associado às maiores densidades populacionais em pastos mais baixos, evidencia a existência de um mecanismo de compensação em pastos de capim-marandu, amplamente descrito na literatura (Grant et al., 1983; Bircham \& Hodgson, 1983; Sbrissia et al., 2001, 2003), segundo o qual pastos mantidos mais baixas possuem maior densidade populacional de perfilhos pequenos e vice-versa.

Além disso, os perfilhos de capim-marandu foram mais pesados no início da primavera, provavelmente em virtude da maior quantidade de tecidos mortos aderidos nos perfilhos nessa época do ano e do acúmulo de biomassa resultante de restrições nas condições de ambiente. Como o crescimento proveniente de folhas e colmos foi muito pequeno (Sbrissia, 2004), boa parte do material produzido via fotossíntese pode ter sido acumulada sem gerar crescimento correspondente. Esse fato é condizente com as variações nos valores de área foliar por perfilho (Tabela 4) e área foliar específica (Figura 4) ao longo do ano. Os menores valores para essas variáveis foram observados durante o início da primavera, ou seja, em uma época em que praticamente não houve crescimento (taxas pequenas de alongamento foliar; Sbrissia, 2004). Desse modo, como forma de adaptação às condições ambientais, os perfilhos passaram a produzir folhas com área de limbo reduzida.

Diversos autores têm apontado a existência de relação inversa entre área foliar específica e longevidade de folhas em diferentes espécies (Van der Werf et al., 1998; Ryser \& Urbas, 2000; Casper et al., 2001). Sbrissia (2004) também observou correlação inversa $(-0,74)$ significativa entre essas variáveis para o capim-marandu e sugeriu um mecanismo de "economia de recursos" em épocas de estresse causado por variáveis ambientais. As maiores áreas foliares registradas nos perfilhos obtidos nas pastos mantidos mais altos (Tabela 4) foram conseqüência direta dos limites plásticos impostos para essa característica, ou seja, o comprimento de folhas teve que se adaptar às reduções em altura do dossel por meio do "encurtamento" de suas lâminas foliares.

A relação folha:colmo (FC) e a razão área foliar:volume (R) dos perfilhos apresentaram tendência distinta. Enquanto a FC diminuiu (Tabela 5) com o aumento da altura do pasto, o valor de $\mathrm{R}$ aumentou (Tabelas 6 e 7).

A razão área foliar:volume $(\mathrm{R})$ foi proposta por SackvilleHamilton et al. (1995). Em seu cálculo, a área foliar dos perfilhos é elevada à potência de $3 / 2$ para tornar seu valor 


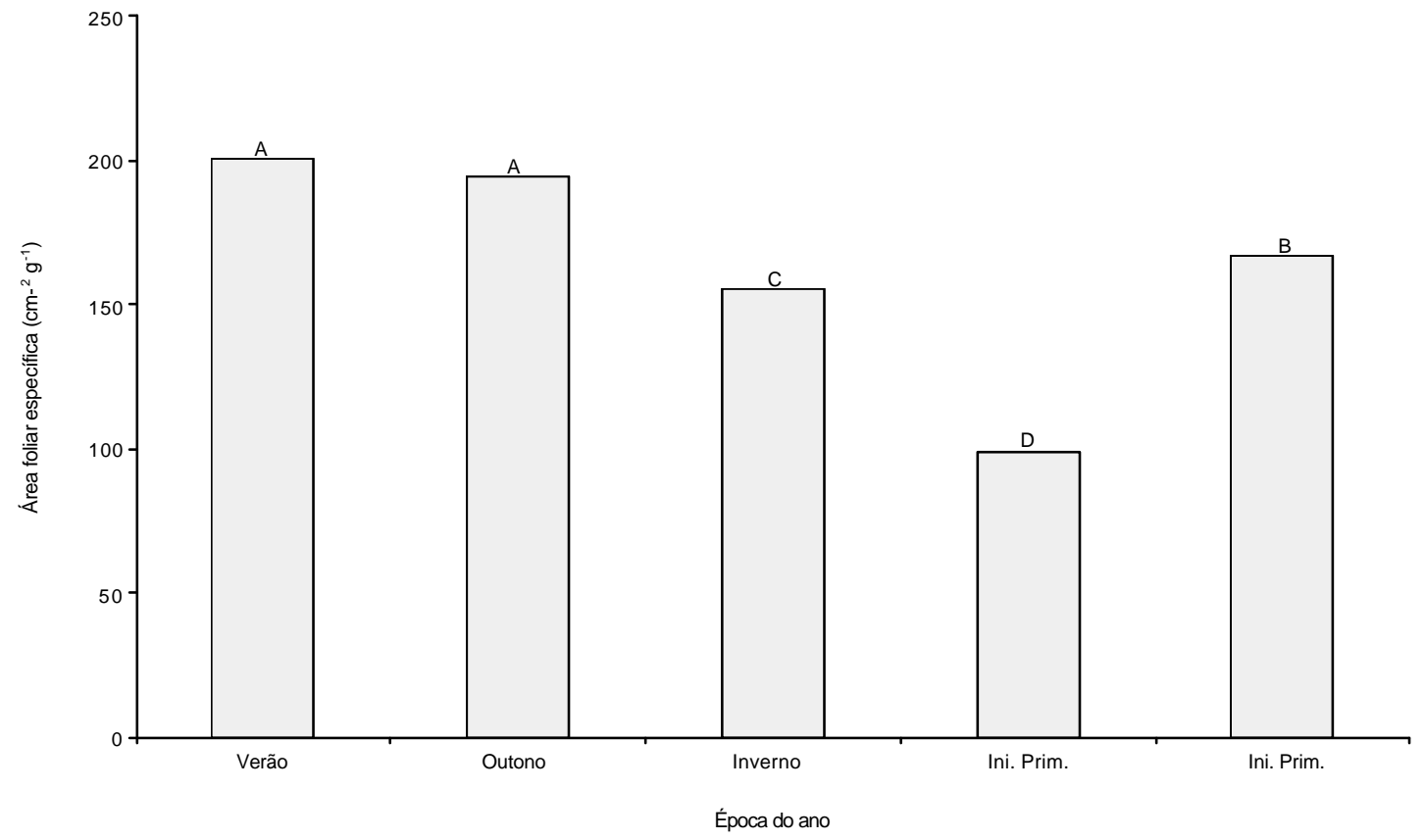

Figura 4 - Área foliar específica $\left(\mathrm{cm}^{2} / \mathrm{g}\right)$ em pastos de capim-marandu em diferentes épocas do ano. Valores seguidos de mesma letra nas colunas não diferem $(P>0,10)$.

Tabela 4 - Área foliar média por perfilho $\left(\mathrm{cm}^{2}\right)$ em pastos de capim-marandu mantidos em quatro alturas de dossel forrageiro por meio de lotação contínua em diferentes épocas do ano

\begin{tabular}{lcccccc}
\hline Época do ano & \multicolumn{4}{c}{ Altura $(\mathrm{cm})$} & Média & Erro-padrão da média \\
\cline { 2 - 5 } & 10 & 20 & 30 & 40 & \\
\hline Verão & $23,3 \mathrm{dAB}$ & $47,2 \mathrm{cA}$ & $61,9 \mathrm{bB}$ & $75,2 \mathrm{aB}$ & $51,9 \mathrm{~B}$ & 1,36 \\
Outono & $31,1 \mathrm{cA}$ & $47,4 \mathrm{bAB}$ & $71,7 \mathrm{aA}$ & $84,3 \mathrm{aA}$ & $58,6 \mathrm{~A}$ & 2,85 \\
Inverno & $28,6 \mathrm{cA}$ & $38,9 \mathrm{cABC}$ & $63,6 \mathrm{bAB}$ & $77,4 \mathrm{aAB}$ & $52,1 \mathrm{~B}$ & 2,75 \\
Início primavera & $19,2 \mathrm{cB}$ & $32,2 \mathrm{bC}$ & $37,5 \mathrm{abC}$ & $43,0 \mathrm{aC}$ & $32,9 \mathrm{C}$ & 1,17 \\
Final primavera & $27,8 \mathrm{dA}$ & $36,7 \mathrm{cBC}$ & $59,9 \mathrm{bB}$ & $78,5 \mathrm{aAB}$ & $50,7 \mathrm{~B}$ & 1,46 \\
Média & $26,0 \mathrm{~d}$ & $41,1 \mathrm{c}$ & $60,2 \mathrm{~b}$ & $73,0 \mathrm{a}$ & & \\
Erro-padrão da média & 2,57 & 2,57 & 2,57 & 2,57 & & \\
\hline
\end{tabular}

Médias seguidas da mesma letra minúscula na linha e maiúscula na coluna não diferem $(P>0,10)$ pelo teste $t$.

Erro-padrão da média da interação: verão $=2,72$, outono $=5,70$, inverno $=5,50$, início primavera $=2,34$ e final primavera $=2,96$

Tabela 5 - Relação folha:colmo de perfilhos individuais em pastos de capim-marandu mantidos em quatro alturas de dossel forrageiro por meio de lotação contínua em diferentes épocas do ano

\begin{tabular}{lllllll}
\hline Época do ano & \multicolumn{9}{c}{ Altura $(\mathrm{cm})$} & \multirow{2}{*}{ Média } & Erro-padrão da média \\
\cline { 2 - 5 } & 10 & 20 & 30 & 40 & $0,63 \mathrm{C}$ & 0,035 \\
\hline Verão & $0,77 \mathrm{aC}$ & $0,66 \mathrm{aB}$ & $0,64 \mathrm{aA}$ & $0,46 \mathrm{bB}$ & $0,77 \mathrm{~B}$ & 0,035 \\
Outono & $1,12 \mathrm{aB}$ & $0,81 \mathrm{bAB}$ & $0,58 \mathrm{cA}$ & $0,59 \mathrm{cAB}$ & $0,89 \mathrm{~A}$ & 0,035 \\
Inverno & $1,39 \mathrm{aA}$ & $0,86 \mathrm{bA}$ & $0,65 \mathrm{cA}$ & $0,68 \mathrm{cA}$ & $0,75 \mathrm{~B}$ & 0,035 \\
Início primavera & $1,14 \mathrm{aB}$ & $0,75 \mathrm{bAB}$ & $0,57 \mathrm{cA}$ & $0,52 \mathrm{cAB}$ & $0,70 \mathrm{C}$ & 0,035 \\
Final primavera & $0,78 \mathrm{aC}$ & $0,66 \mathrm{aB}$ & $0,71 \mathrm{aA}$ & $0,64 \mathrm{aA}$ & & \\
Média & $1,02 \mathrm{a}$ & $0,75 \mathrm{~b}$ & $0,63 \mathrm{c}$ & $0,58 \mathrm{c}$ & & \\
Erro-padrão da média & 0,029 & 0,030 & 0,030 & 0,032 & & \\
\hline
\end{tabular}

*Erro-padrão da média.

Médias seguidas da mesma letra minúscula na linha e maiúscula na coluna não diferem entre si pelo teste $t(P>0,10)$.

Erro-padrão da média da interação: 0,070. 
Tabela 6 - Razão área foliar:volume por perfilho assumindo volume calculado baseado em densidade constante de $950 \mathrm{~kg} / \mathrm{m}^{3} \mathrm{em} \mathrm{pastos}$ de capim-marandu mantidos em quatro alturas de dossel forrageiro por meio de lotação contínua em diferentes épocas do ano

\begin{tabular}{|c|c|c|c|c|c|c|}
\hline Época do ano & \multicolumn{4}{|c|}{ Altura $(\mathrm{cm})$} & Média & Erro-padrão da média \\
\hline Verão & $64,0 \mathrm{bB}$ & $82,6 \mathrm{aB}$ & $94,1 \mathrm{aBC}$ & $93,2 \mathrm{aB}$ & $83,5 \mathrm{C}$ & 2,73 \\
\hline Inverno & $85,5 \mathrm{cA}$ & $87,8 \mathrm{bcB}$ & $110,6 \mathrm{abAB}$ & $117,5 \mathrm{aA}$ & $100,3 \mathrm{~B}$ & 4,90 \\
\hline Início primavera & $51,3 \mathrm{abB}$ & $65,5 \mathrm{aC}$ & $46,0 \mathrm{bD}$ & $59,7 \mathrm{abC}$ & $55,6 \mathrm{D}$ & 3,21 \\
\hline Final primavera & $58,0 \mathrm{~dB}$ & $68,2 \mathrm{cC}$ & $93,8 \mathrm{bC}$ & $115,7 \mathrm{aA}$ & $83,9 \mathrm{C}$ & 1,86 \\
\hline
\end{tabular}

Médias seguidas da mesma letra minúscula na linha e maiúscula na coluna não diferem $(P>0,10)$ pelo teste $t$.

Erro-padrão da média da interação: verão $=5,46$, outono $=6,44$, inverno $=9,80$, início primavera $=6,42$ e final primavera $=3,72$.

Tabela 7 - Razão área foliar:volume por perfilho calculada com os valores de volume efetivamente medidos em pastos de capim-marandu mantidos em quatro alturas de dossel forrageiro por meio de lotação contínua em diferentes épocas do ano

\begin{tabular}{lcccrrr}
\hline Época do ano & \multicolumn{4}{c}{ Altura $(\mathrm{cm})$} & Média & \multirow{2}{*}{ Erro-padrão da média } \\
\cline { 2 - 5 } & 10 & 20 & 30 & 40 & $106,7 \mathrm{~A}$ & 5,69 \\
\hline Inverno & $82,8 \mathrm{bA}$ & $104,0 \mathrm{abA}$ & $113,8 \mathrm{aA}$ & $126,3 \mathrm{aA}$ & $53,8 \mathrm{C}$ & 2,57 \\
Início da primavera & $57,2 \mathrm{aB}$ & $78,8 \mathrm{aB}$ & $62,4 \mathrm{aC}$ & $57,1 \mathrm{aC}$ & $\mathrm{B}$ & \\
Final primavera & $61,3 \mathrm{bB}$ & $69,2 \mathrm{bB}$ & $97,0 \mathrm{aB}$ & $103,9 \mathrm{aB}$ & $95,8 \mathrm{a}$ & \\
Média & $67,1 \mathrm{~b}$ & $84,0 \mathrm{ab}$ & $91,0 \mathrm{a}$ & 6,77 & \\
Erro-padrão da média & 6,77 & 6,77 & 6,77 & & \\
\hline
\end{tabular}

Médias seguidas da mesma letra minúscula na linha e maiúscula na coluna não diferem pelo teste $t(P>0,10)$.

Erro-padrão da média da interação: inverno $=11,38$, início da primavera $=11,14$ e final primavera $=4,50$.

adimensional. Segundo Hernández-Garay et al. (1999), avaliações da relação folha:colmo por perfilho são impróprias para efeito de cálculos da compensação tamanho/densidade populacional, uma vez que folha e colmo são componentes da planta que possuem dimensões diferentes e que a relação folha:colmonãoincluiessas diferenças (o colmoé tridimensional e a folha pode ser considerada bidimensional). Desse modo, aumentos na altura do pasto quase sempre conduzem a uma redução concomitante na relação folha:colmo por perfilho pelo fato de que, para suportar o peso de um órgão (no caso as folhas), o diâmetro das estruturas de suporte (no caso os colmos) altera-se em proporção direta à força requerida para suportá-lo e não isometricamente com o seu peso (McMahon, 1973; McMahon \& Kronauer, 1976; Niklas, 1994). Neste experimento, os valores de R elevaram-se com o aumento nas alturas do pasto.

As diferentes metodologias empregadas no cálculo de $\mathrm{R}$ foram utilizadas com o objetivo de comparar estimativas provenientes do uso de um valor genérico aproximado ou de um valor exato de densidade aparente e volume dos perfilhos. Durante o inverno e início da primavera, os valores de $\mathrm{R}$ calculados com base no volume efetivamente medido foram superiores àqueles calculados com a densidade constante (Tabelas 6 e 7), justamente porque nesses períodos os valores de densidade aparente calculados a partir do volume por perfilho efetivamente medido foram superiores a $950 \mathrm{~kg} / \mathrm{m}^{3}$ (Sbrissia et al., 2004), o que acabou elevando os valores de R. Pelo motivo contrário, durante o final da primavera, os valores de $\mathrm{R}$ calculados com base no volume medido foram um pouco menores que aqueles calculados com base em densidade constante, ou seja, a densidade aparente foi menor que $950 \mathrm{~kg} / \mathrm{m}^{3}$ durante aquela época do ano. Essa variação em densidade aparente evidencia que os cálculos de $\mathrm{R}$, sempre que possível, deveriam ser feitos com base no volume efetivamente medido, uma vez que a densidade aparente dos perfilhos variou com as alturas de dossel e as épocas do ano analisadas.

$A$ variação em $R$ significa que, conforme o dossel aumentou em altura, os perfilhos individuais mudaram sua forma, ocasionando aumento maior no componente folha em comparação ao colmo, apesar da redução na relação folha:colmo por perfilho calculada com base apenas em massa. Hernández-Garay et al. (1999) reportaram valores de $\mathrm{R}$ próximos de 50 para azevém perene. Segundo esses autores, estes valores elevaram à medida que a altura do dossel aumentou, indicando que, em azevém perene, ocorrem mudanças na forma do perfilho que correspondem a um aumento maior em área foliar relativamente ao comprimento 
do colmo à medida que as plantas aumentam em tamanho. No entanto, neste trabalho, os valores máximos de $\mathrm{R}$ foram mais elevados, enquanto Sbrissia et al. $(2001,2003)$ encontraram nos capins coastcross e tifton-85 valores de $\mathrm{R}$ em torno de 17.

Segundo Matthew et al. (2000), variações interespecíficas em $\mathrm{R}$ poderiam ter algumas implicações ecológicas. Segundo esses autores, plantas com valores maiores de $\mathrm{R}$ podem ter maior habilidade competitiva baseada em tolerância ao pastejo (Briske, 1996), enquanto plantas com valores menores de $\mathrm{R}$ poderiam ser mais resistentes a estresses, pois menor razão área foliar:volume seria um mecanismo de a planta evitar perda de água, por exemplo. O baixo valor de $\mathrm{R}$ durante o início da primavera em comparação a outras épocas do ano pode ser um indicativo de que, além das variações interespecíficas comentadas por Matthew et al. (2000), podem existir variações intraespecíficas, como uma resposta às modificações de ambiente. No caso do capimmarandu, os perfilhos, provavelmente na tentativa de reduzir a perda de água, reduziram sua área foliar em relação ao volume, sugerindo capacidade adaptativa plástica muito interessante quanto à estratégia de perenização e sobrevi- vência para essa planta. A variação sazonal nos valores de $\mathrm{R}$ pode estar relacionada à inversão na dinâmica de fluxo de tecidos em perfilhos individuais entre as épocas do ano (Sbrissia, 2004). Durante o início da primavera, as taxas de senescência foliar foram, em média, duas vezes maiores que as de alongamento (único período do ano em que a senescência foi maior que o alongamento), o que reduziu o número de folhas vivas por perfilho contribuindo para a redução nos valores de $\mathrm{R}$ naquela época do ano. Além disso, a translocação de nutrientes das folhas em senescência para as folhas vivas pode ter contribuído para a redução da área foliar específica, cujo valor mais baixo foi registrado no início da primavera (Figura 4).

Os coeficientes angulares da relação funcional entre $\log$ da massa e log da densidade populacional de perfilhos (valor $\beta$ ) foram menores que a proposição teórica de $-3 / 2$ ou $-1,50$, amplamente descrita na literatura e sugerida para relações dessa natureza (Yoda et al., 1963; Kays \& Harper, 1974; Lonsdale \& Watkinson, 1982) (Tabelas 8 e 9). Segundo Sackville-Hamilton et al. (1995), uma reta de inclinação -3/2 seria uma expectativa teórica quando o IAF e a razão área foliar:volume por perfilho $(\mathrm{R})$ permanecessem constantes.

Tabela 8 - Coeficientes da regressão entre o log da densidade populacional de perfilhos e o log da massa média por perfilho. Inclinação predita estimada pressupondo uma densidade aparente constante de $950 \mathrm{~kg} \cdot \mathrm{m}^{-3}$ no cálculo de $\mathrm{Cr}$

\begin{tabular}{|c|c|c|c|c|c|}
\hline Coeficiente* & Regressão & $\mathrm{C}_{\mathrm{a}}$ & $\mathrm{C}_{\mathrm{r}}$ & $\mathrm{C}_{\mathrm{d}}$ & Inclinação predita \\
\hline & & & Verão & & \\
\hline$\beta$ & $-3,92 \quad(0,53)$ & $3,67(0,99)$ & $-1,19(0,30)$ & & $-3,98$ \\
\hline$\beta_{0}$ & $14,75(1,61)$ & & & & \\
\hline $\mathrm{R}^{2}$ & 0,96 & 0,84 & 0,86 & & \\
\hline \multirow[t]{2}{*}{$\mathrm{P}$} & 0,0396 & 0,15 & 0,14 & & \\
\hline & & & Outono & & \\
\hline$\beta$ & $-3,41 \quad(1,04)$ & $2,84(1,08)$ & $-0,91 \quad(0,27)$ & & $-3,43$ \\
\hline$\beta_{0}$ & $12,99(3,09)$ & & & & \\
\hline $\mathrm{R}^{2}$ & 0,79 & 0,65 & 0,81 & & \\
\hline \multirow[t]{2}{*}{$\mathrm{P}$} & 0,20 & 0,35 & 0,19 & & \\
\hline & & & Inverno & & \\
\hline$\beta$ & $-2,05 \quad(0,40)$ & $1,12(0,30)$ & $-0,58 \quad(0,06)$ & $0,06(0,02)$ & $-2,10$ \\
\hline$\beta_{0}$ & $8,77(1,15)$ & & & & \\
\hline $\mathrm{R}^{2}$ & 0,92 & 0,84 & 0,99 & 0,78 & \\
\hline \multirow[t]{2}{*}{$\mathrm{P}$} & 0,08 & 0,16 & 0,019 & 0,22 & \\
\hline & & & Início da primavera & & \\
\hline$\beta$ & $-1,70(0,34)$ & $0,76(0,34)$ & $-0,54 \quad(0,27)$ & $0,15(0,04)$ & $-1,87$ \\
\hline$\beta_{0}$ & $7,85 \quad(0,98)$ & & & & \\
\hline $\mathrm{R}^{2}$ & 0,91 & 0,48 & 0,08 & 0,84 & \\
\hline \multirow[t]{2}{*}{$P$} & 0,08 & 0,52 & 0,91 & 0,16 & \\
\hline & & & Final da primavera & & \\
\hline$\beta$ & $-2,88 \quad(0,74)$ & $3,18(0,96)$ & $-2,02 \quad(0,38)$ & $0,18(0,08)$ & $-2,84$ \\
\hline$\beta_{0}$ & $11,27(2,16)$ & & & & \\
\hline $\mathrm{R}^{2}$ & 0,86 & 0,80 & 0,92 & 0,30 & \\
\hline $\mathrm{P}$ & 0,14 & 0,20 & 0,07 & 0,7 & \\
\hline
\end{tabular}

${ }^{*} \beta$ = coeficiente angular, $\beta_{0}=$ coeficiente linear, $\mathrm{R}^{2}=$ coeficiente de determinação e $\mathrm{P}=$ significância. ${ }^{\ddagger}$ calculada segundo Matthew et al. (1995), de modo que inclinação $=-\left(\mathrm{C}_{\mathrm{a}}+\mathrm{C}_{\mathrm{r}}+\mathrm{C}_{\mathrm{d}}+3 / 2\right)$

Os valores entre parênteses correspondem ao desvio-padrão dos coeficientes. 
Tabela 9 - Coeficientes de regressão entre o log da densidade populacional de perfilhos e o log da massa média por perfilho. Inclinação predita estimada pressupondo densidade aparente variável no cálculo de $\mathrm{Cr}$

\begin{tabular}{|c|c|c|c|c|c|}
\hline Coeficiente $^{*}$ & Regressão & $\mathrm{C}_{\mathrm{a}}^{\dagger}$ & $\mathrm{C}_{\mathrm{r}}^{\dagger}$ & $\mathrm{C}_{\mathrm{d}}^{\dagger}$ & Inclinação predita \\
\hline & & & Verão & & \\
\hline$\beta$ & $-3,92(0,53)$ & $3,67(0,99)$ & $-1,19(0,30)$ & $\mathrm{NC}$ & $-3,98$ \\
\hline$\beta_{0}$ & $14,75(1,61)$ & & & & \\
\hline $\mathrm{R}^{2}$ & 0,96 & 0,84 & 0,86 & & \\
\hline \multirow[t]{2}{*}{$\mathrm{P}$} & 0,0396 & 0,15 & 0,14 & & \\
\hline & & & Outono & & \\
\hline$\beta$ & $-3,41(1,04)$ & $2,84(1,08)$ & $-0,91(0,27)$ & $\mathrm{NC}$ & $-3,43$ \\
\hline$\beta_{0}$ & $12,99(3,09)$ & & & & \\
\hline $\mathrm{R}^{2}$ & 0,79 & 0,65 & 0,81 & & \\
\hline \multirow[t]{2}{*}{$\mathrm{P}$} & 0,20 & 0,35 & 0,19 & & \\
\hline & & & Inverno & & \\
\hline$\beta$ & $-2,05(0,40)$ & $1,12(0,30)$ & $-0,65(0,14)$ & $\mathrm{NC}$ & $-1,97$ \\
\hline$\beta_{0}$ & $8,77(1,15)$ & & & & \\
\hline $\mathrm{R}^{2}$ & 0,92 & 0,84 & 0,99 & & \\
\hline \multirow[t]{2}{*}{$\mathrm{P}$} & 0,08 & 0,16 & 0,019 & & \\
\hline & & & Início da primavera & & \\
\hline$\beta$ & $-1,70(0,34)$ & $0,76(0,34)$ & $-0,52(0,24)$ & $\mathrm{NC}$ & $-1,74$ \\
\hline$\beta_{0}$ & $7,85(0,98)$ & & & & \\
\hline $\mathrm{R}^{2}$ & 0,91 & 0,48 & 0,08 & & \\
\hline \multirow[t]{2}{*}{$\mathrm{P}$} & 0,08 & 0,52 & 0,91 & & \\
\hline & & & Final da primavera & & \\
\hline$\beta$ & $-2,88(0,74)$ & $3,18(0,96)$ & $-1,73(0,47)$ & $\mathrm{NC}$ & $-2,95$ \\
\hline$\beta_{0}$ & $11,27(2,16)$ & & & & \\
\hline $\mathrm{R}^{2}$ & 0,86 & 0,80 & 0,92 & & \\
\hline $\mathrm{P}$ & 0,14 & 0,20 & 0,07 & & \\
\hline
\end{tabular}

${ }^{\star} \beta=$ coeficiente angular, $\beta_{0}=$ coeficiente linear, $R^{2}=$ coeficiente de determinação e $P=$ significância; ${ }^{\dagger} C_{a}, C_{r}$ e $C_{d}=$ correções para variações em IAF, $R$ e densidade aparente, respectivamente; $\ddagger$ calculada segundo Matthew et al. (1995), de modo que inclinação $=-\left(C_{a}+C_{r}+C_{d}+3 / 2\right)$.

Os valores entre parênteses correspondem ao desvio-padrão dos coeficientes.

$\mathrm{NC}=$ não calculado.

Além disso, o modelo matemático proposto por esses autores considera que possíveis variações em densidade aparente dos perfilhos também poderiam explicar as variações na inclinação predita da reta. No entanto, considerando as dificuldades em estimar a densidade aparente de perfilhos, têm-se assumido valores de densidade aparente constantes ao longo de uma ampla faixa de variação em alturas do dossel, de modo que as correções têm sido feitas com base em variações no IAF e em $\mathrm{R}$ apenas (Matthew et al., 1995; Sackville-Hamilton et al., 1995; Sbrissia et al., 2001; 2003).

As correções para IAF e R foram propostas por Matthew et al. (1995) e denominadas $C_{a}$ e $C_{r}$, respectivamente. Os modelos propostos por esses autores também consideram a possibilidade de variações em densidade aparente dos perfilhos, que, neste trabalho, geram um novo fator de correção, $\mathrm{C}_{\mathrm{d}}$, uma vez que a metodologia desenvolvida e utilizada para estimar o volume dos perfilhos foi satisfatória, pois sua densidade aparente pôde ser efetivamente calculada (Sbrissia et al., 2004).

As três correções definem uma correção $\mathrm{C}$, em que $\mathrm{C}=\mathrm{C}_{\mathrm{a}}+\mathrm{C}_{\mathrm{r}}+\mathrm{C}_{\mathrm{d}}$, que representa uma mudança vertical hipotética na reta-referência de inclinação -3/2. Para explicar $\mathrm{C}_{\mathrm{a}}$, considera-se que aumentos no tamanho dos perfilhos ocorrem com o aumento em altura do dossel. Desse modo, o IAF do pasto também aumenta. A variação na inclinação da linha de compensação tamanho/densidade populacional de perfilhos (coeficiente $\alpha$ ) em relação ao valor teórico de $-3 / 2$ pode ser definida como o deslocamento da linha de um IAF constante (-3/2) para outra linha de IAF também constante, porém comvalor de intercepto (coeficiente $\beta_{0}$ ) mais alto, o que geraria uma nova linha com inclinação maior em relação à reta $-3 / 2$ e a correção seria expressa como o aumento teórico em densidade populacional de perfilhos necessário para alcançar a nova linha de IAF constante ou como uma mudança no intercepto da linha teórica de IAF constante (Matthew et al., 1995). O C ${ }_{\mathrm{r}}$ poderia ser explicado como variações na forma do perfilho à medida que ocorrem variações em densidade populacional para alturas variáveis de dossel. Assim, se uma grande modificação na forma do perfilho não é acompanhada por um aumento compatível em

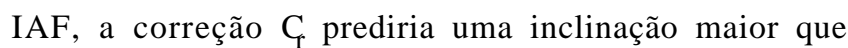
$-3 / 2$, uma vez que a correção $C$ é o resultado da soma de $C_{a}$, 
$\mathrm{C}_{\mathrm{r}}$ e $\mathrm{C}_{\mathrm{d}}$ e que o $\mathrm{C}_{\mathrm{r}}$ assume normalmente um valor negativo (Matthew et al., 1995). A variação em $\mathrm{C}_{\mathrm{d}}$ pode ser explicada como o resultado de um mecanismo segundo o qual os perfilhos compactariam mais biomassa por unidade de volume, o que, em última instância, reduziria a competição por espaço e, conseqüentemente, a captação de recursos. Por outro lado, se a soma de $\mathrm{C}_{\mathrm{a}}, \mathrm{C}_{\mathrm{r}}$ e $\mathrm{C}_{\mathrm{d}}$ é igual a zero, a inclinação da reta seria $-3 / 2$.

Dados com azevém perene mostraram que $C_{a}$ possui valor próximo de 2,0 e $\mathrm{C}_{\mathrm{r}}$ próximo de - 0,2 , indicando que o valor $\mathrm{R}$, por aumentar em pastos mais altos, reduziu a inclinação da reta predita por $\mathrm{C}_{\mathrm{a}}$ - (Matthew et al., 2000). Essas duas correções praticamente explicaram a discrepância entre a inclinação teórica de -3/2 e o valor realmente observado para os dados coletados e analisados. Matthew et al. (1995) observaram inclinações para azevém próximas de $-5 / 2$ e verificaram que algumas observações anteriores a essa (Davies, 1988) também confirmaram as conclusões daqueles autores. Em outro experimento, Hernández-Garay et al. (1999) obtiveram inclinação para azevém perene de -2,56 e inclinação predita pelas correções $C_{a}$ e $C_{r}$ de -2,68, confirmando que as correções foram capazes de explicar, para plantas de clima temperado, as diferenças entre as inclinações observadas e a expectativa teórica de $-3 / 2$ $(-1,50)$. Sbrissia et al. $(2001,2003)$, em pesquisa com os capins coastcross e tifton 85 , também verificaram variações maiores em $\mathrm{C}_{\mathrm{a}}$ em comparação àquelas em $\mathrm{C}_{\mathrm{r}}$. Essas correções explicaram os desvios entre a inclinação real e a teórica de $-3 / 2$ em tifton 85 nas diferentes épocas do ano. Para o coastcross, isso só ocorreu no período de verão.

Os valores de $\mathrm{C}_{\mathrm{a}}, \mathrm{C}_{\mathrm{r}}$ e $\mathrm{C}_{\mathrm{d}}$ para o capim-marandu calculados foram eficazes em explicar os desvios entre as inclinações obtidas e as expectativas teóricas de $-3 / 2$ durante todos os períodos avaliados (Tabela 8 ). No entanto, as regressões utilizadas para estimar os valores de $C_{a}$ e $C_{r}$, quase sempre, não foram significativas $(\mathrm{P}>0,10)$, portanto, optou-se por apresentar os desvios dos coeficientes angulares e considerar a discussão com base nessas limitações. As correções para mudança na forma dos perfilhos $\left(C_{r}\right)$ foram estimadas de duas maneiras.Na primeira, assumiu-se uma densidade aparente constante dos perfilhos $\left(950 \mathrm{~kg} / \mathrm{m}^{3}\right)$ e os volumes correspondentes estimados. Nesse caso, como a densidade era constante, gerou-se um novo fator de correção $\left(\mathrm{C}_{\mathrm{d}}\right)$ usando os dados de densidade efetivamente medidos. Durante os períodos de verão e outono, não foi possível calcular essa última correção porque as medições de volume foram consistentes somente a partir de julho. De todas as correções, $\mathrm{C}_{\mathrm{d}}$ foi a menor, indicando que as variações em densidade aparente foram pequenas e pouco mo dificaram os valores preditos por $\mathrm{C}_{\mathrm{a}}$ e $\mathrm{C}_{\mathrm{r}}$ (Tabela 8). Além disso, $\mathrm{C}_{\mathrm{a}}$ foi a maior correção em todas as avaliações, indicando que variações em IAF foi o principal determinante dos ajustes nas retas de compensação. Apesar disso, durante o início da primavera, os valores de $C_{a}$ e $C_{r}$ foram muito próximos, indicando mudanças na forma dos perfilhos, provavelmente como forma de adaptação às condições de ambiente desfavoráveis naquela época do ano. Na outra forma de cálculo, $\mathrm{C}_{\mathrm{r}}$ foi calculado a partir dos valores de volume efetivamente medidos (Tabela 9). Nesse caso, não foram calculadas as variações em $C_{d}$, uma vez que as variações em densidade aparente já teriam sido consideradas por variações conjuntas na massa e no volume dos perfilhos. Como resultado, as duas correções $\left(\mathrm{C}_{\mathrm{a}}\right.$ e $\left.\mathrm{C}_{\mathrm{r}}\right)$ forameficazes em predizer a inclinação da reta efetivamente obtida por meio das regressões entre $\log$ da densidade populacional e log da massa por perfilho, indicando que, em situações nas quais é possível a medição do volume dos perfilhos, não é necessária a introdução de um fator de correção para densidade aparente. Nos casos em que estimativa do volume é baseada em densidade aparente constante e pré-determinada, deve-se atentar para o fato de que possíveis discrepâncias entre os coeficientes angulares observados (inclinações das retas) e a linha de referência -3/2 podem advir de possíveis variações em densidade aparente, embora esse efeito seja menor.

Ao longo dos períodos de avaliação, as inclinações das retas de compensação foram diminuindo a partir do verão (Tabelas 8 e 9) e voltaram a aumentar apenas no final da primavera. Essa redução em inclinação significa que, conforme as estações avançaram, aumentos em massa resultaram em reduções proporcionalmente maiores no número de perfilhos, principalmente nos pastos mantidos a 30 e $40 \mathrm{~cm}$. A segmentação dos coeficientes angulares entre as alturas de dossel estudadas (Tabela 10) indica que apenas durante o verão houve aumentos em altura do dossel até $40 \mathrm{~cm}$ e que esses aumentos não prejudicaram a densidade populacional associada à massa de perfilhos tomando-se por referência a linha de -3/2. Durante as épocas de inverno e início da

Tabela 10 - Coeficientes angulares $(\beta)$ das relações entre o log da densidade populacional de perfilhos e o log da massa média por perfilhos

\begin{tabular}{lccc}
\hline Época do ano & \multicolumn{3}{c}{$\begin{array}{c}\text { Coeficiente angular dos } \\
\text { segmentos de reta entre } \\
\text { alturas do pasto }\end{array}$} \\
\cline { 2 - 4 } & $\Delta_{10-20}$ & $\Delta_{20-30}$ & $\Delta_{30-40}$ \\
\hline Verão & $-7,44$ & $-2,34$ & $-2,86$ \\
Outono & $-8,45$ & $-12,67$ & $-0,46$ \\
Inverno & $-7,12$ & $-1,70$ & $-0,58$ \\
Início de primavera & $-4,42$ & $-1,66$ & $-0,56$ \\
Final de primavera & $-5,46$ & $-8,20$ & $-0,63$ \\
\hline
\end{tabular}

(c) 2008 Sociedade Brasileira de Zootecnia 
primavera, as inclinações entre as alturas de 20 e $30 \mathrm{~cm}$ foram próximas de -3/2 (-1,50), o que, segundo a teoria proposta por Sackville-Hamilton et al. (1995), indica que o IAF do dossel tendeu a se manter constante a partir de $20 \mathrm{~cm}$ de altura, fato confirmado nas avaliações de IAF (Tabela 11). À exceção do período de verão, durante todas as outras épocas do ano, não houve vantagens em aumentar a altura do dossel além de $30 \mathrm{~cm}$, uma vez que as inclinações foram menores que -1 , indicando que a perda de perfilhos foi proporcionalmente maior que o aumento médio em massa média por perfilho.

O diagrama multifásico proposto por Matthew et al. (1995) sugere que inclinações próximas de -1 representariam valores constantes de massa de forragem no dossel (condição clímax). O produto entre os valores de densidade populacional de perfilhos (Tabela 2) e os de massa dos perfilhos (Tabela 3 ) indica reduções na massa de forragem a partir da altura de $30 \mathrm{~cm}$, comprovando a conceituação teórica proposta por Matthew et al. (1995). Portanto, em termos de produção de forragem, não há vantagem em se manter os pastos em alturas superiores a $30 \mathrm{~cm}$ durante a maior parte do ano (exceção feita ao verão), uma vez que, durante os períodos de inverno e início de primavera, esse valor passaria a ser $20 \mathrm{~cm}$, evidenciando que a otimização da produção em pastos de capim-marandu ocorreria por meio de ajustes sazonais na altura do dossel. Dados de acúmulo de forragem (Molan, 2004) e dinâmica do acúmulo de matéria seca (Sbrissia, 2004) obtidos no mesmo período experimental e com a mesma planta forrageira também sustentam esta observação.

Tabela 11 - Índice de área foliar de pastos de capim-marandu mantidos em quatro alturas de dossel forrageiro por meio de lotação contínua em diferentes épocas do ano

\begin{tabular}{|c|c|c|c|c|c|c|}
\hline \multirow[t]{2}{*}{ Época do ano } & \multicolumn{4}{|c|}{ Altura $(\mathrm{cm})$} & \multirow[t]{2}{*}{ Média } & \multirow[t]{2}{*}{ Erro-padrão da média } \\
\hline & 10 & 20 & 30 & 40 & & \\
\hline Verão & $3,0 \mathrm{cAB}$ & $5,6 \mathrm{bA}$ & $6,6 \mathrm{abA}$ & $6,7 \mathrm{aA}$ & $5,5 \mathrm{~A}$ & 0,19 \\
\hline Outono & $3,4 \mathrm{cA}$ & $4,8 \mathrm{bA}$ & $6,7 \mathrm{aA}$ & $6,2 \mathrm{aA}$ & $5,3 \mathrm{~A}$ & 0,24 \\
\hline Inverno & $2,7 \mathrm{bB}$ & $3,4 \mathrm{abB}$ & $4,2 \mathrm{aB}$ & $4,0 \mathrm{aC}$ & $3,5 \mathrm{~B}$ & 0,23 \\
\hline Início primavera & $1,8 \mathrm{cC}$ & $2,3 \mathrm{abC}$ & $2,6 \mathrm{aC}$ & $2,1 \mathrm{bD}$ & $2,2 \mathrm{C}$ & 0,07 \\
\hline Final primavera & $2,7 \mathrm{bAB}$ & $3,2 \mathrm{bB}$ & $5,0 \mathrm{aB}$ & $5,0 \mathrm{aB}$ & $4,0 \mathrm{~B}$ & 0,20 \\
\hline Média & $2,7 \mathrm{c}$ & $4,0 \mathrm{~b}$ & $5,3 \mathrm{a}$ & $5,1 \mathrm{a}$ & & \\
\hline Erro-padrão da média & 0,21 & 0,20 & 0,20 & 0,20 & & \\
\hline
\end{tabular}

Médias seguidas da mesma letra minúscula na linha e maiúscula na coluna não diferem $(P>0,10)$ pelo teste $t$.

Erro-padrão da média da interação: verão $=0,38$, outono $=0,48$, inverno $=0,46$, início da primavera $=0,14$ e final da primavera $=0,40$.

\section{Conclusões}

As inclinações de reta obtidas sugerem que pastos de capim-marandu podem exigir variações sazonais em seu manejo, com valores de altura de no máximo $30 \mathrm{~cm}$ (sob lotação contínua) durante o período de final de primavera e verão e de 10 a $20 \mathrm{~cm}$ durante o período de outono-inverno. Além disso, variações em IAF, razão área foliar:volume e densidade aparente por perfilho explicam os desvios das retas em relação à inclinação de $-3 / 2$.

\section{Agradecimento}

À FAPESP, pela concessão da bolsa de estudos, e aos membros da equipe de trabalho: Adriano Vecchiatti Lupinacci, Alexandre Campos Gonçalves, Daniel Oliveira de Lucena Sarmento, Leonardo Kehdi Molan e Flávia Maria Erbetta de Andrade.

\section{Literatura Citada}

BIRCHAM, J.S.; HODGSON, J. The influence of sward condition on rates of herbage growth and senescence in mixed swards under continuous stocking management. Grass and Forage Science, v.38, n.4, p.323-331, 1983.

CASPER, B.B.; FORSETH, I.N.; KEMPENICH, H. et al. Drought prolongs leaf life span in the herbaceous desert perennial Cryptantha flava. Functional Ecology, v.15, n.6, p.740-747, 2001.

DAVIES, A. The regrowth of grass swards. In: JONES, M.B.; LAZENBY, A. (Eds.) The grass crop. London: Chapman and Hall, 1988. p.85-127.

EMPRESA BRASILEIRA DE PESQUISA AGROPECUÁRIA EMBRAPA. Sistema brasileiro de classificação de solos. Brasília: 1999. 412p. (Produção de Informação).

FAGUNDES, J.L.; DA SILVA, S.C.; PEDREIRA, C.G.S. et al. Índice de área foliar, interceptação luminosa e acúmulo de forragem em pastagens de Cynodon spp. Sob diferentes intensidades de pastejo. Scientia Agricola, v.56, n.4, p.1141-1150, 1999.

HERNÁNDEZ-GARAY, A.H.; MATTHEW, C.; HODGSON, J. Tiller size/density compensation in perennial ryegrass miniature swards subject to differing defoliation heights and a proposed productivity index. Grass and Forage Science, v.54, n.4 p.347-356, 1999. 
GRANT, S.A.; BARTHRAM, G.T.; TORVELL, L. et al. Sward management, lamina turnover and tiller population-density in continuously stocked lolium-perenne-dominated swards. Grass and Forage Science, v.38, n.4, p.333-344, 1983.

KAYS, S.; HARPER, J.L. The regulation of plant and tiller density in a grass sward. Jounal of Ecology, v.62, p.97-105, 1974.

LABARBERA, M. Analyzing body size as a factor in ecology and evolution. Annual Review of Ecology and Systematics, v.20, p.97-117, 1989.

LEMAIRE, G.; CHAPMAN, D. Tissue flows in grazed plant communities. In: HODGSON, J.; ILLIUS A.W. (Eds.). The ecology and management of grazing systems. London: CAB International, 1996. p.3-36.

LITTEL, R.C.; PENDERGAST, J.; NATARAJAN, R. Modelling covariance structure in the analysis of repeated measures data. Statistics in Medicine, v.19, p.1793-1819, 2000.

MATTHEW, C. A study of seasonal root and tiller dynamics in swards of perennial ryegrass (Lolium perenne L.). Palmerston North, 1992. 210p. Thesis (Ph.D.) - Massey University, 1992.

MATTHEW, C.; LEMAIRE, G.; HAMILTON, N.R.S. et al. A modified self-thinning equation to describe size/density relationships for defoliated swards. Annals of Botany, v.76, n.6, p.579-587, 1995.

MATTHEW, C.; ASSUERO, S.G.; BLACK, C.K. et al. Tiller dynamics of grazed swards. In: LEMAIRE, G.; HODGSON, J.; MORAES, A. et al. (Eds.) Grassland ecophysiology and grazing ecology. Wallingford: CABI Publishing, 2000. p.127-150.

MOLAN, L.K. Estrutura do dossel, interceptação luminosa e acúmulo de forragem em pastos de capim-Marandu submetidos a alturas de pastejo por meio de lotação contínua. Piracicaba: Escola Superior de Agricultura Luiz de Queiroz, 2004. 159p. Dissertação (Mestrado em Agronomia Ciência Animal e Pastagens) - Escola Superior de Agricultura Luiz de Queiroz, 2004.

PARSONS, A.J.; LEAFE, E.L.; COLLETT, B. et al. The physiology of grass production under grazing. 1. Characteristics of leaf and canopy photosynthesis of continuously-grazed swards. Journal of Applied Ecology, v.20, n.1, p.117-126, 1983.

PEDREIRA, C.G.S. Avanços metodológicos na avaliação de pastagens. In: REUNIÃO ANUAL DA SOCIEDADE BRASIEIRA DE ZOOTECNIA, 39., 2002, Recife. Anais... Recife: Sociedade Brasileira de Zootecnia, 2002. v.1, p.100-150.

PETERNELLI, M. Características morfogênicas e estruturais do Capim-braquiarão [Brachiaria brizantha (hochst ex a. rich.) stapf. cv. marandu] sob intensidades de pastejo.
Pirassununga: Universidade de São Paulo, 2003. 79p. Dissertação (Mestrado em Zootecnia) - Universidade de São Paulo, 2003.

PRETZSCH, H. A unified law of spatial allometry for woody and herbaceous plants. Plant Biology, v.4, n.2, p.159-166, 2002.

RYSER, P.; URBAS, P. Ecological significance of leaf life span among Central European grass species.Oikos, v.91, n.1, p41$50,2000$.

SACKVILLE-HAMILTON, N.R.; MATTHEW, C.; LEMAIRE, G. In defence of the $-3 / 2$ boundary rule: a re-evaluation of self thinning concepts and status. Annals of Botany, v.76, p.569577, 1995.

SBRISSIA, A.F. Morfogênese, dinâmica do perfilhamento e do acúmulo de forragem em pastos de capim-Marandu sob lotação contínua. Piracicaba: Escola Superior de Agricultura Luiz de Queiroz, 2004, 171p. Tese (Doutorado em Agronomia - Ciência Animal e Pastagens) - Escola Superior de Agricultura Luiz de Queiroz, 2004.

SBRISSIA, A.F.; DA SILVA, S.C.; CARVALHO, C.A.B. et al. Tiller size/population density compensation in Coastcross grazed swards. Scientia Agrícola, v.58, n.4, p.655-665, 2001.

SBRISSIA,A.; DA SILVA, S.; MATTHEW, C. et al. Tiller size/density compensation in grazed Tifton 85 bermudagrass swards. Pesquisa Agropecuária Brasileira, v.38, n.12, p.1459-1468, 2003.

SBRISSIA, A.F.; DA SILVA, S.C.; MOLAN, L.K. et al. A simple method for measuring tiller volume of grasses. Grass and Forage Science, v.59, p.406-410, 2004.

Van der WERF, A.; GEERTS, R.H.E.M.; JACOBS, F.H.H. et al. The importance of relative growth rate and associated traits for competition between species during vegetational succession. In: LAMBERS, H.; POORTER, H.; van VUUREN, M.M.I. (Eds.). Inherent variation in plant growth: physiological mechanisms and ecological consequences. Backhuys: Backhuys Publishers, 1998. p.489-502.

Van RAIJ, B.; QUAGGIO, J.A.; SILVA, N.M. Extraction of phosphorus, potassium, calcium, and magnesium from soils by ion-exchange resin procedure. Communications in Soil Science and Plant Analysis, v.17, n.5, p.547-566, 1986.

WeStoBy, M. The self-thinning rule. Advances in Ecological Research, v.14, p.41-76, 1984.

WOLFINGER, R.D. Covariance structure selection in general mixed models. Communications in Statistics Simulation and Computation, v.22, n.4, p.1079-1106, 1993.

YODA, K.; KIRA, T.; OGAWA, H. et al. Intraspecific competition among higher plants. XI Self-thinning in overcrowded pure stands under cultivate and natural conditions. Journal of Institute of Polytechnics, v.14, p.107-129, 1963. 